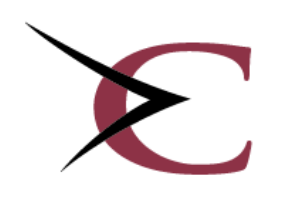

\title{
cirano
}

Allier savoir et décision

\section{$2015 s-48$}

\section{Consumer preferences for improved hen} housing: Is a cage a cage?

Maurice Doyon, John Cranfield, Stéphane Bergeron, Lota D. Tamini and George Criner 


\title{
2015s-48 \\ Consumer preferences for improved hen housing: Is a cage a cage?
}

\author{
Maurice Doyon, John Cranfield, Stéphane Bergeron, \\ Lota D. Tamini and George Criner
}

\section{Série Scientifique \\ Scientific Series}

\section{Montréal \\ Octobre/October 2015}

(C) 2015 Maurice Doyon, John Cranfield, Stéphane Bergeron, Lota D. Tamini and George Criner. Tous droits réservés. All rights reserved. Reproduction partielle permise avec citation du document source, incluant la notice $($ ).

Short sections may be quoted without explicit permission, if full credit, including $@$ notice, is given to the source.

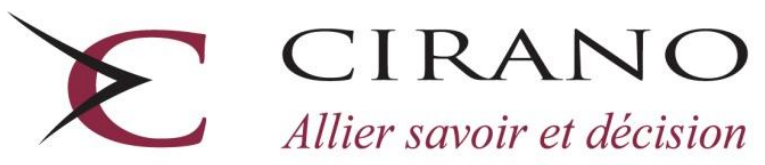

Centre interuniversitaire de recherche en analyse des organisations 


\section{CIRANO}

Le CIRANO est un organisme sans but lucratif constitué en vertu de la Loi des compagnies du Québec. Le financement de son infrastructure et de ses activités de recherche provient des cotisations de ses organisations-membres, d'une subvention d'infrastructure du Ministère de l'Économie, de l'Innovation et des Exportations, de même que des subventions et mandats obtenus par ses équipes de recherche.

CIRANO is a private non-profit organization incorporated under the Québec Companies Act. Its infrastructure and research activities are funded through fees paid by member organizations, an infrastructure grant from the Ministère de l' l'Économie, de l'Innovation et des Exportations, and grants and research mandates obtained by its research teams.

\section{Les partenaires du CIRANO}

\section{Partenaires corporatifs}

Autorité des marchés financiers

Banque de développement du Canada

Banque du Canada

Banque Laurentienne du Canada

Banque Nationale du Canada

Bell Canada

BMO Groupe financier

Caisse de dépôt et placement du Québec

Fédération des caisses Desjardins du Québec

Financière Sun Life, Québec

Gaz Métro

Hydro-Québec

Industrie Canada

Intact

Investissements PSP

Ministère de l'Économie, de l'Innovation et des Exportations

Ministère des Finances du Québec

Power Corporation du Canada

Rio Tinto

Ville de Montréal

Partenaires universitaires

École Polytechnique de Montréal

École de technologie supérieure (ÉTS)

HEC Montréal

Institut national de la recherche scientifique (INRS)

McGill University

Université Concordia

Université de Montréal

Université de Sherbrooke

Université du Québec

Université du Québec à Montréal

Université Laval

Le CIRANO collabore avec de nombreux centres et chaires de recherche universitaires dont on peut consulter la liste sur son site web.

Les cahiers de la série scientifique (CS) visent à rendre accessibles des résultats de recherche effectuée au CIRANO afin de susciter échanges et commentaires. Ces cahiers sont écrits dans le style des publications scientifiques. Les idées et les opinions émises sont sous l'unique responsabilité des auteurs et ne représentent pas nécessairement les positions du CIRANO ou de ses partenaires.

This paper presents research carried out at CIRANO and aims at encouraging discussion and comment. The observations and viewpoints expressed are the sole responsibility of the authors. They do not necessarily represent positions of CIRANO or its partners.

ISSN 2292-0838 (en ligne) 


\title{
Consumer preferences for improved hen housing: Is a cage a cage?*
}

\author{
Maurice Doyon ${ }^{\dagger}$, John Cranfield ${ }^{\ddagger}$, Stéphane Bergeron ${ }^{\S}$, \\ Lota D. Tamini** and George Criner ${ }^{\dagger \dagger}$
}

\begin{abstract}
There is growing concern amongst some consumers regarding animal welfare in livestock production. Several regions, including California and the European Union, have banned the use of battery cage production systems for laying hens. In Quebec, battery cages are being phased out with new barns required to be equipped with enriched cages. In this paper, the empirical data from two discrete choice experiments (DCE) are used to understand Quebec consumers' demand for alternative laying hen housing systems and desired attributes. The results of the first DCE suggest that Quebec consumers are not willing to pay a premium for eggs produced in enriched cage systems, in spite of evidence that they prefer aspects of that system. Using an online survey we find that consumers have a negative stigma related to the word 'cage'. A second DCE is therefore conducted to estimate consumer preferences for different amenities commonly found in enriched cage systems, without the possible negative framing effect from the word "cage". The results suggest that consumers have a positive value for the enhanced housing system for laying hens, results also indicate a differentiated demand for the various elements of the enhanced system.
\end{abstract}

\section{Résumé}

Les consommateurs sont de plus en plus soucieux du bien-être animal. Plusieurs régions, incluant la Californie et l'Europe, interdissent l'élevage de poules dans des systèmes de cages traditionnelles. Au Québec, ce type de cage sera graduellement éliminé, les producteurs ayant collectivement décidé que les nouvelles constructions seront équipées de cages enrichies. Ce papier présence les résultats de deux enquêtes avec choix expérimentaux discrets (CED) qui permettent de mieux comprendre la demande des consommateurs québécois pour les différents éléments d'un système de cage enrichie. La première enquête démontre une absence de valeur positive pour ce système, bien que les éléments du système de cage enrichie soient valorisés. Une enquête en ligne démontre un fort biais négatif associé au mot cage. Un deuxième CED, qui n'utilise pas le mot cage, est utilisé pour déterminer les préférences des consommateurs pour les différents éléments d'un système de cage enrichie. Les résultats indiquent une valeur positive pour le système enrichie avec des valeurs différenciées selon les éléments qui composent ce système de logement des pondeuses.

Mots clés/keywords : eggs, choice experiment, framing, enhanced cage, furnished cage

\footnotetext{
* La Fédération des producteurs d'oeufs du Québec, The Poultry Industry Council, the Ontario Ministry of Agriculture (OMAFRA) and the Egg Industry Economic Research Chair are gratefully acknowledged.

$\dagger$ Université Laval

$\$$ University of Guelph

$\S$ Université Laval

** Université Laval

$\dagger$ University of Maine
} 


\section{INTRODUCTION}

There is growing concern amongst some consumers regarding animal welfare in livestock production. Several regions, including California and the European Union, have banned the use of battery cage production systems for laying hens. In Canada, egg farmers' boards are taking voluntary measures to improve the welfare of hens. In Quebec, for example, battery cages are being phased out with new barns required to be equipped with enriched cages that offer hens increased space and other amenities including scratch pads, dust baths, perches and nesting area. Since switching housing systems implies increased production costs (Sumner et al. 2008), it is imperative that consumer demand for eggs produced in alternative housing systems be properly understood. Several studies have examined consumer demand for hen welfare (Bennett and Blaney 2003; Chang, Lusk, and Norwood 2010; Andersen 2011; Lusk and Norwood 2011) but little has been done to understand which enriched cage features are valued by consumers.

In this paper, the empirical data from two discrete choice experiments (DCE) are used to understand Quebec consumers' demand for alternative laying hen housing systems and desired attributes. The first DCE examines three classes of housing systems: enriched cages, free run and free range eggs. The results suggest that Quebec consumers are not willing to pay a premium for eggs produced in enriched cage systems, in spite of evidence that they prefer aspects of that system. This apparent contradiction suggests that there may be a negative stigma associated with the word "cage" that outweighs the positive preferences for certain enriched cage features. The field of psychology has researched the issue of framing, and finds that a negative framing ( $10 \%$ chance of death vs $90 \%$ chance of survival) is powerful, and preference reversals are possible depending on how questions are framed (Peters, Finucane, MacGregor, and Slovic 2000). In the food literature we see that the choice of words may have an unexpected effect on consumer preference since they can be associated with prior beliefs (Costanigro, Deselnicu, and Kroll 2015). Therefore perceptions to specific words to describe 
attributes need to be examined carefully prior to eliciting values for value added food products (Liaukonyte et al. 2013). We find using an online survey that consumers do in fact have a negative stigma related to the word 'cage'.

Under the hypothesis that the negative framing with "cage" resulted in our inability to find a value for the Enriched Cage, a second DCE is conducted using 'Eco-Natural Housing' as the name for the enriched cage system. This survey focuses on estimating consumer preferences for different amenities commonly found in enriched cage systems, without the possible negative framing effect from the word "cage". The results suggest that consumers appear to have a positive value for the enhanced housing system for laying hens. The inclusion of a perch and a nesting area are most valued, while increased living space, dust baths and scratch pads are given little value.

Our results have two important implications for policy makers and egg farmers. First, rather than Quebec consumer preferences being driven by space per hen, we see a more complex relation based on specific housing features. For example, the inclusion of scratch pad had no significant value for consumers. Second, the identified negative stigma associated with the word "cage" implies that care must be taken when communicating food attributes and farming systems to consumers.

The paper is organized as follows. In the next two sections we discuss methodology and present the results from the two DCEs. Following this we include a discussion on policy implications, then offer concluding remarks.

\section{METHODS AND RESULTS}

\section{DCE1: Preference for housing system}

Our first experiment draws on previous work that sought to explain demand for eggs from alternative housing systems across different regions of Canada. A conditional logit model (see Wang et al. 2015) was applied to stated choice data to explore whether preferences for attributes of housing systems differ across Canadian provinces/regions. 
From this dataset, we report only the estimates for the province of Quebec, with 342 and 339 completed surveys per treatment respectively. Our main interest, for the purpose of this paper, is the valuation given to each production systems. However, the original dataset and results from Wang et al. (2015) provide values for two treatments, differentiated by the information provided; with and without the inclusion of scientific evidence on how the housing system impacts hen welfare.

The attributes used in designing hypothetical products in this choice experiment were: price; housed in cage; access to outdoor; the inclusion of nest boxes, perches for roosting and scratching area for dust bathing; and the space allowance. Attribute levels are provided in Table 1. A randomized block design was used to construct choice sets, with respondents randomly assigned to a particular survey (Louviere et al. 2000). Each choice task included eight choice sets. Respondents were asked which of two hypothetical egg products they would choose. To avoid forcing a choice on respondents, an opt-out option was available in each choice set. The data was analyzed using a conditional logit model with an alternative-specific constant (ASC) to account for the opt-out option (see, for example, Haaijer, Kamakura, and Wedel 2001 and Birol, Karousakis, and Koundouri. 2006).

Table 1 : Attributes and levels used for the first choice experiment.

\begin{tabular}{lc}
\hline \multicolumn{1}{c}{ Attributes } & Levels \\
\hline \hline & \\
Price (\$CDN/dozen) & $\$ 2.80 ; \$ 3.80 ; \$ 4.80 ; \$ 5.80$ \\
Space (sq. in) & $69 ; 110 ; 171 ; 252$ \\
Raised in cages & Yes - No \\
Outdoor access & Yes - No \\
Nest boxes, perches for roosting & \\
and scratching area for dust & \\
bathing are present & Yes - No \\
\hline
\end{tabular}

Estimates from the conditional logit model for Quebec of DCE1 are reported in Table 2; note that space was entered as a continuous variable in this model. Qualitatively 
identical results were obtained across both treatments. The coefficient on price is significant and, as expected, has a negative sign (Wang et al. 2015). Regardless of treatment, the estimate on the housing system using cages was not significant. However, estimates on access to the outdoors is significant and positive, as is the coefficient indicating whether the housing systems is equipped with nest boxes, perches and scratching area. The coefficient on the space allowance variable is also significant and marginally positive. Lastly, the coefficient on ASC (the alternative specific constant) was significant in each treatment. While the estimates are interesting in themselves, their value comes to bear when they are translated into marginal willingness-to-pay for the respective attribute.

Table 2. Conditional logit results for Quebec, experiment 1

\begin{tabular}{|l|l|l|}
\hline & Treatment 1 & Treatment 2 \\
\hline Price & $-0.736^{* * *}$ & $-0.622^{* * *}$ \\
\hline & $(0.000)$ & $(0.000)$ \\
\hline System uses cage & -0.062 & -0.020 \\
\hline & $(0.206)$ & $(0.669)$ \\
\hline Outdoor access & $0.434^{* * *}$ & $0.424^{* * *}$ \\
\hline & $(0.000)$ & $(0.000)$ \\
\hline Nest boxes, perches and scratch area & $0.189^{* * *}$ & $0.277^{* * *}$ \\
\hline & $(0.000)$ & $(0.000)$ \\
\hline Space allowance & $0.003^{* * *}$ & $0.001^{*}$ \\
\hline & $(0.000)$ & $(0.074)$ \\
\hline ASC & $2.334^{* * *}$ & $2.204^{* * *}$ \\
\hline & $(0.000)$ & $(0.000)$ \\
\hline & & \\
\hline Number of Observations & 2736 & 2712 \\
\hline Pseudo R2 & 0.1651 & 0.1421 \\
\hline
\end{tabular}

Note: $\mathrm{P}$-values are shown in parentheses statistical significance is denoted as follow: ${ }^{*} p<0.1 * *$ $p<0.05^{* * *} p<0.01$

Table 3 shows the results marginal WTP values, calculating using the coefficient on the price attribute (Louviere et al. 2000), for both treatments along with their corresponding significance levels calculated using the bootstrap approach proposed by Krinsky and Robb (1986). These results, although not statistically significant, suggest that 
respondents have a negative marginal willingness-to-pay for a dozen eggs of either $\$ 0.084$ or $-\$ 0.033$ (depending on treatment), when eggs are from hens housed in systems that use cages. The absence of a positive value suggests that consumers do not value the cage element of an enhanced cage system, which is quite problematic if egg farmers are expected to invest in converting barns to an enriched system. At the same time, a positive value was found for the aggregate of amenities include in enriched cages (between $\$ 0.19$ and $\$ 0.28$ per dozen depending on treatment), which suggests that prior beliefs could be associated with the word "cage".

Table 3. MWTP (CND\$/dozen) for experiment 1, Quebec results

\begin{tabular}{lll}
\hline & $\begin{array}{c}\text { Treatment 1 } \\
\text { WTP }\end{array}$ & $\begin{array}{c}\text { Treatment 2 } \\
\text { WTP }\end{array}$ \\
\hline \hline No cage & -0.084 & -0.033 \\
Outdoor & $0.589 * * *$ & $0.682^{* * *}$ \\
Nest, perch, scratch & $0.257^{* * *}$ & $0.445^{* * *}$ \\
Space & $0.004 * * *$ & $0.002 *$ \\
\hline
\end{tabular}

Note: $P$-values are shown in parameters and statistical significance is denote as follow: ${ }^{*} p<0.1$ $* * p<0.05 * * * p<0.01$

To examine possible stigma related to the word "cage", we conducted an online survey using the "Survey Monkey» platform to measure how respondents believed hen's welfare improved based on the name given to the housing systems, without any additional information. In the survey participants rated the level of comfort given to the hens solely based on 12 different names used to describe the housing system ${ }^{2}$. Figure 1 indicates that the three names containing the word cage were by far the least preferred option amongst the 75 respondents. On the other hand, the preferred name was Eco-

\footnotetext{
${ }^{2}$ The names of the hen housing system are fictive and were created by the researchers.
} 
Natural. These results support the hypothesis that the lack of value given to caged housing can be explained by the negative stigma associated with the word "cage".

Figure 1 Classification of perceived hen welfare (HW) based on housing system names

\section{Preferences for amenities in enriched cage (DCE2)}

The second DCE was designed as a complement to the previous one, and seeks to verify if a positive value exists for specific enriched cage features in the absence of the framing effect associated with the word cage. The DCE design will help identify the amenities of an enriched housing system are valued by consumers. In addition, by segmenting consumers based upon their declared motivation for buying alternative production method eggs (organic, free range and free run), we can assess the potential impact of consumers' motivations when making purchase choices.

The DCE asked respondents to declare the choice they would make between a dozen eggs from a conventional housing system and the Eco-Natural housing system. The following six attributes varied for the Eco-Natural eggs; price, space, perch, nesting area, scratching pad and dust bath, with levels given in Table 4. The 'conventional cage' kept the same attributes for all choice sets with a cost of $\$ 3.39,67$ sq. in. of space and the no amenities included. For the six attributes of housing system (Table 4) a description of how they improved hen welfare was provided, along with some negative side effects that have been raised in the literature. Participants were also informed that the information had previously been validated by experts in the field. The survey used a 2 block orthogonal design, such that each respondent answered a total of 8 choices sets, presented in a random order. 
Table 4 : Attributes and levels used for the enriched cage eggs choice.

\begin{tabular}{|c|c|}
\hline Attributes & Levels \\
\hline Price (\$CDN/dzn) & $\begin{array}{llll}3.39 & 3.69 & 4.49 & 6.99\end{array}$ \\
\hline Space (sq. in) & $67-93$ \\
\hline Perch & Yes - No \\
\hline Nesting Area & Yes - No \\
\hline Scratching Pad & Yes - No \\
\hline Dust bath & Yes - No \\
\hline
\end{tabular}

The survey was conducted by a professional firm that targeted a representative sample of the Quebec population. A narrative video with illustration presented the key information relating to hen housing and enriched cage features. The dataset is from 572 respondents ${ }^{3}$ who answered the choice sets and a series question on purchase habits and standard socioeconomic information. The survey included a question asking respondents who declared having previously purchased free run, free range or organic eggs to give the main reason they purchased these types of eggs. From these answers we created three subgroup of consumers as follows: (i) the "self-interest» group represents consumers that justify their purchase for food safety, nutrition or for better taste reasons; (ii) the "for the hen" group are consumers who buy value-added eggs in consideration for the hens' welfare; and (iii) the "for the environment» group purchase value-added eggs since they believe that they are better for the environment. In order to obtain marginal WTP based on attributes of the enriched cage system we used a DCE with a multinomial logit model to estimate coefficients for each cage attribute and calculated marginal WTP estimates using the coefficients of the price attribute. The

\footnotetext{
${ }^{3}$ The initial data set had 602 respondents. We removed all the questionnaires that had logical inconsistencies regarding strictly dominating choices, suggesting that these respondents acted like professional survey takers, answering as fast as possible without consideration of the survey objet, in order to get a reward. Nevertheless, the model was run with the full sample $(n=602)$ without any effect on the results, but an improved statistical significance with the reduced sample.
} 
model was analysed using the mlogit package (Croissant 2013) in R statistical language (R Core Team 2015).

\section{Results}

In contrast to the DCE experiment using the word "cage," the second model finds a statistically significant positive value for enriched cage eggs denominated as 'EcoNatural,' for the full sample $(n=572)$ among all consumer subgroups modelled. This result supports the framing hypothesis with the word 'cage,' which negatively influences perception of the housing systems.

For the full sample we find that increased space per hen is not valued by the consumer. The other amenities all have statistically positive coefficients, with WTP of $\$ 0.53(p<$ $0.005)$ for a Nesting Box, $\$ 0.31(p<0.005)$ for the Perch, $\$ 0.17(p<0.05)$ for the Scratching Pad and $\$ 0.15(p<0.05)$ for the Dust Bath. The intercept has a value greater than one dollar $(p<0.005)$, which is interpreted as the utility for eggs from hens lodged in the Eco-Natural housing system that cannot be attributed individually to the listed attributes. Results are presented in Table 5.

Table 5 : Estimates of a multinomial Logit model on with willingness to pay estimates.

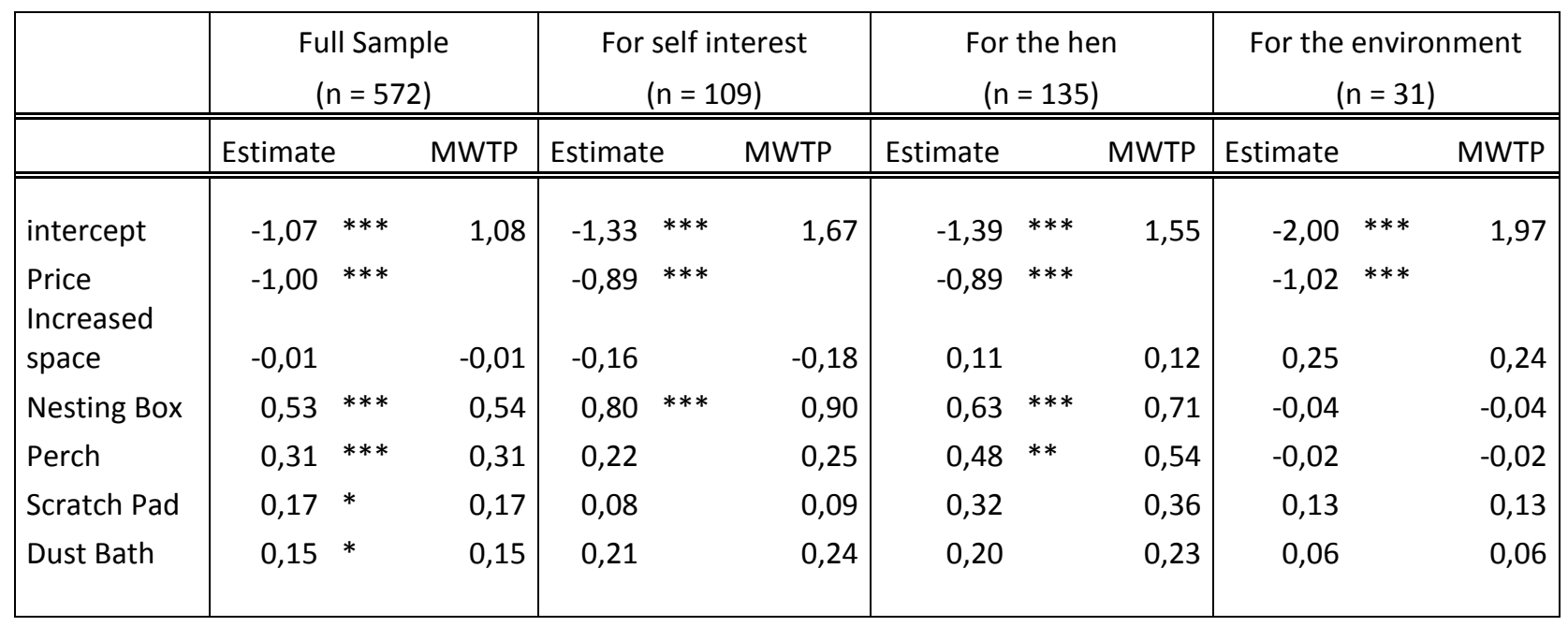

Looking at the subgroups we find that no group has a positive valuation for increasing the space allocation per hen. Consumers with self-interest justification most value the 
nesting box at $\$ 0.90$ per dozen, while those with concerns for hens' welfare value the perch and the nesting box at $\$ 0.71$ and $\$ 0.54$, respectively. The 'For the environment' group does not have any statistically significant MWTP for the studied attributes. Nevertheless, this group has a general positive value of $\$ 1.97$ per dozen of eggs from Eco-Naturel housing, above their value for regular eggs. From the MWTP amounts estimated with the above model we calculate how much each subgroup is willing to pay for a dozen of eggs from the Eco-Naturel housing system, when including all amenities, compared to eggs from conventional housing systems. The full sample is willing to pay \$2.24 more per dozen, the self-interest group \$ 3.31 more, the hen welfare group would pay $\$ 3.38$ more, and the environmental group $\$ 2.10$ more.

\section{DISCUSSION}

The empirical results from two DCE surveys allow us to better understand consumer demand for improved housing systems. The results from the first DCE suggest that consumers do not value eggs from enriched systems that use cages. Further evidence of this is reflected in Figure 1, which shows that respondents in Quebec perceive use of cages as having the least favourable impact on hen welfare, presumably because of the use of cages.

The data from the second DCE provides further insight into the features that are valued by consumers. It does so by using a different framing of the use of cages, and an alternative naming for enriched cage-housing systems. Specifically we call these systems an Eco-Naturel housing system, and do so to avoid the strong framing effect associated with the word cage. We estimated positive premiums for a dozen eggs from the enriched housing ranging from $\$ 2.10$ to $\$ 3.38$, depending on the consumer profile. Note that these premiums could be impacted by a hypothetical bias problem. Therefore, theses prices should not be taken at face value, but as indicators of relative preferences for the cage attributes (the order remains valid). 
The nesting box and perch have the highest valuation respectively. Based on consumer profiles, it would seem that consumers perceive the nesting box to provide both benefits for the hen's welfare and contribute to safer and better quality eggs. The inclusion of the perch was only valued by respondents whose main motive was to increase hen's welfare, suggesting that consumers do not believe that this will increase egg quality.

Surprisingly, increased space allowance per hen did not receive a positive valuation from any of the consumer groups. In fact, one choice set in the survey included the option increasing space from 67 to 93 square inches at an additional cost of \$1.10 without adding any other feature. Only $34 \%$ of respondents were willing to pay this amount, compared to $55 \%$ who were willing to pay the same amount for a nesting box, without an increased in space.

A potential explanation would be that the increased in space is not judged sufficient to improve hens' welfare. The participants were told that 93 square inches represents roughly the size of a regular piece of paper. Moreover, this seems to be confirmed by results from the first experimental design, which increased in space started at $110 \mathrm{sq}$. and were positively valued. On the other hand, the introduction of a nesting box seems to shift positively the perception on hen welfare. This implies that the negative reaction associated with the word cage is rooted in consumers' aversion to a confined space for hen, in the absence of additional features. The implication of these results for egg farmer is that enhanced housing systems should concentrate on nesting box and perch. Space wise, results indicate that a perceived marginal increase in space is not valued by Quebec consumers. On the other hand, it appears that larger space allowance per hen is positively valued by the same consumers. These results warrant closer examination to assure investment in new housing systems are not mismatched with market demand and further studies are needed to understand the threshold of space needed for hens for it to be valued by consumers. 
The observed high values given to the coefficients of the intercept could be interpreted as the values given to 'Eco-Natural' eggs that are not given for an attribute explicitly presented in the choice set. In support of this assumption, we observe that environmentally minded respondents chose the eco-natural housing eggs while being indifferent towards features. The researchers are aware that future studies should avoid labels from choice set by referring to choices as 'System A' and 'System 'B'. It should be noted, that the in DCE 1 each choice set was labelled as 'Option A' and 'Option B', nevertheless we still observe a high value for the alternative specific constant which is equivalent to the intercept. These high values can also be explained since they capture values for interaction, for example consumers might value the nesting box when combined with increased space more than when these are offered separately.

To justify increased farm level investment in animal welfare systems we must assess the demand for such good as well as the actual benefit for the animal. The discussed studies have shown that some features commonly included in enriched cages, such as dust bath and scratch pads, are not valued by consumers of premium eggs. By segmenting the customers according to their motives when making purchase choices provides insight into the perceived benefits of each attribute.

This study also shows that it is imperative that policy makers and egg boards properly communicate the changes that are taking place in the egg production systems. If enriched cage systems are to become the new norm, communication campaigns should explain how the new housing amenities benefit the hens. With consideration towards the negativity related to the word cage, it might be best to avoid describing this systems as enriched cage, and consider alternative names such as 'housing system'. Furthermore, changes in hen housing systems can have an impact on how consumers currently perceive egg differentiation and modify the current consumption trends. For example, Bajaei et al. 2011 find that the free range eggs consumption has strongly increased in British Colombia from 2007 to 2009. If future hen housing systems include amenities that are perceived as increasing egg quality (nesting box) and hen welfare 
(perch) then the differentiation with regards to the benefits of cage free eggs will be

diminished. Consequently, this might reduce demand for cage free and free run eggs.

Andersen, Laura Mørch. 2011. "Animal Welfare and Eggs - Cheap Talk or Money on the Counter?” Journal of Agricultural Economics 62 (3): 565-84. doi:10.1111/j.14779552.2011.00310.x.

Bejaei, M., K. Wiseman and K. M. Cheng. 2011. Influences of demographic characteristics, attitudes, and preferences of consumers on table egg consumption in British Columbia, Canada. Poultry science 90(5): 1088-1095.

Bennett, Richard M., and Ralph J.P. Blaney. 2003. "Estimating the Benefits of Farm Animal Welfare Legislation Using the Contingent Valuation Method." Agricultural Economics 29 (1): 85-98. doi:10.1111/j.1574-0862.2003.tb00149.x.

Birol, E., K. Karousakis, and P. Koundouri. 2006. "Using a choice experiment to account for preference heterogeneity in wetland attributes: The case of Cheimaditida wetland in Greece." Ecological Economics 60:145-156.

Chang, Jae Bong, Jayson L. Lusk, and F. Bailey Norwood. 2010. "The Price of Happy Hens: A Hedonic Analysis of Retail Egg Prices.” Journal of Agricultural and Resource Economics 35 (3). http://ideas.repec.org/a/ags/jlaare/97855.html.

Costanigro, Marco, Oana Deselnicu, and Stephan Kroll. 2015. "Food Beliefs: Elicitation, Estimation and Implications for Labeling Policy." Journal of Agricultural Economics 66 (1): 108-28. doi:10.1111/1477-9552.12085.

Haaijer, R., W. Kamakura, and M. Wedel. 2001. "The no-choice alternative in conjoint choice experiments." International Journal of Market Research 43:93-106.

Liaukonyte, Jura, Nadia A. Streletskaya, Harry M. Kaiser, and Bradley J. Rickard. 2013. "Consumer Response to 'Contains' and 'Free Of' Labeling: Evidence from Lab Experiments.” Applied Economic Perspectives and Policy, ppt015.

Louviere, Jordan J., David A. Hensher, and Joffre D. Swait. Stated Choice Methods: Analysis and Applications. 1st ed. Cambridge University Press, 2000.

Lu, Y. (2013). Consumer Preference for Eggs from Enhanced Animal Welfare Production System: A Stated Choice Analysis (M.Sc. Thesis).

Lusk, Jayson L., and F. Bailey Norwood. 2011. "Speciesism, Altruism and the Economics of Animal Welfare." European Review of Agricultural Economics, July, jbr015. doi:10.1093/erae/jbr015.

Croissant, Yves. 2013. Package 'mlogit: multinomial logit model'. R package version 0.2-4. http://CRAN.R-project.org/package=mlogit

R Core Team (2015). ' $R$ : A language and environment for statistical computing. R Foundation for Statistical Computing', Vienna, Austria. URL http://www.R-project.org/.

Wang, Grace, John Cranfield, Yiqing Lu and Tina Widowski. 2015. Do Consumers' Preferences for Enhanced Animal Welfare Food Products Vary Across Regions of Canada? Evidence from a Stated Choice Analysis. Draft manuscript, University of Guelph. 
Tél. : 514-985-4000 • Téléc. : 514-985-4039

www.cirano.qc.ca・info@cirano.qc.ca 